\title{
Management of COPD, equal treatment across age, gender, and social situation? A register study
}

\author{
This article was published in the following Dove Press journal: \\ International Journal of COPD \\ 26 October 2016 \\ Number of times this article has been viewed
}

Ingela Henoch ${ }^{1,2}$

Susann Strang',2

Claes-Göran Löfdahl',3

Ann Ekberg-Jansson ${ }^{1,4}$

'Angered Hospital, Research and Development Department, ${ }^{2}$ The Sahlgrenska Academy, Institute of Health and Care Sciences, University of Gothenburg, Gothenburg, 3University of Lund, Lund,

${ }^{4}$ Sahlgrenska Academy, Institute of Medicine, University of Gothenburg, Gothenburg, Sweden
Correspondence: Ingela Henoch Sahlgrenska Academy, University of Gothenburg, Institute of Health and

Care Sciences, Box 457, SE-405 30

Gothenburg, Sweden

$\mathrm{Tel}+46317866092$

Email ingela.henoch@gu.se
Abstract: Chronic obstructive pulmonary disease (COPD) is a progressive chronic disease where treatment decisions should be based on disease severity and also should be equally distributed across age, gender, and social situation. The aim of this study was to determine to what extent patients with COPD are offered evidence-based interventions and how the interventions are distributed across demographic and clinical factors in the sample. Baseline registrations of demographic, disease-related, and management-related variables of 7,810 patients in the Swedish National Airway Register are presented. One-third of the patients were current smokers. Patient-reported dyspnea and health-related quality of life were more deteriorated in elderly patients and patients living alone. Only $34 \%$ of currently smoking patients participated in the smoking cessation programs, and $22 \%$ of all patients were enrolled in any patient education program, with women taking part in them more than men. Less than $20 \%$ of the patients had any contact with physiotherapists or dieticians, with women having more contact than men. Men had more comorbidities than women, except for depression and osteoporosis. Women were more often given pharmacological treatments. With increasing severity of dyspnea, participation in patient education programs was more common. Dietician contact was more common in those with lower body mass index and more severe COPD stage. Both dietician contact and physiotherapist contact increased with deteriorated health-related quality of life, dyspnea, and increased exacerbation frequency. The present study showed that COPD management is mostly equally distributed across demographic characteristics. Only a minority of the patients in the present study had interdisciplinary team contacts. Thus, this data shows that the practical implementation of structured guidelines for treatment of COPD varies, to some extent, with regard to age and gender. Also, disease characteristics influence guideline implementation for each individual patient. Quality registers have the strength to follow-up on compliance with guidelines and show whether an intervention needs to be adapted prior to implementation in health care practice.

Keywords: COPD, quality register, treatments, socioeconomic status, lung

\section{Background}

Chronic obstructive pulmonary disease (COPD) is a progressive illness that, in advanced condition, has limited survival and severe health changes that demand preventive and alleviating measures to reduce the impact of exacerbations. ${ }^{1}$ COPD is unevenly distributed in the population, as people of the lowest socioeconomic status who have COPD are more likely to experience poor health outcomes than those of the highest socioeconomic status with COPD. ${ }^{2}$ Smoking, the main cause of the disease, is also related to socioeconomic status. ${ }^{3}$ There are also gender differences: women with COPD are more likely to report the prevalence and higher intensity of dyspnea;, women have lower prevalence of cardiovascular comorbidity and diabetes mellitus; 
and osteoporosis and depression are more common in women. ${ }^{4}$ In a study exploring gender differences in the use of diagnostic tools and nonmedical treatment, it was found that a minority of patients had undergone spirometry tests, women had them done less often than men, but more smoking cessation advice was given to women. ${ }^{5}$ Deterioration in health-related quality of life (HRQOL) has been associated with severity of COPD and increasing age. ${ }^{6}$ With increasing age, the risk of exacerbations is increased, ${ }^{7-9}$ and naturally, a fatal outcome is more common. ${ }^{9,10}$

The negative influence of progression of the disease is highly significant in patients, which necessitates the development of both pharmacological and nonpharmacological evidence-based management strategies. Of the nonpharmacological treatments, patient education has been shown to have an effect on the number of general practitioner visits, patient satisfaction, ${ }^{11}$ hospital admissions, and HRQOL. ${ }^{12}$ Pulmonary rehabilitation improves both dyspnea and exercise capacity, ${ }^{13}$ reduces the number of hospitalizations, and decreases mortality. ${ }^{14}$ Therefore, physiotherapists play an important role in the management of COPD ${ }^{15}$ Other effective nonpharmacological interventions for patients are dietician consultation for patients with low body mass index (BMI) and smoking cessation programs for smokers. Pharmacological treatments in severe COPD should include long-acting anticholinergics and/or long-acting $\beta_{2}$-adrenoceptor agonists and/or a combination of long-acting $\beta_{2}$-adrenoceptor agonists and inhaled corticosteroids. ${ }^{16}$ Despite the existing research, the distribution of disease manifestations and treatments must be further explored in larger samples of COPD patients. The distribution of treatments across sociodemographic characteristics, such as age, gender, and social situation and disease severity, needs to be explored.

Clinical quality registers could be used to observe the course of the disease in real life, in order to understand variations in treatment and outcomes ${ }^{17}$ and whether the treatments are equally distributed. The Swedish National Airway Register was introduced in 2009 in Sweden and in 2012, the model was transformed to include asthma also. The present study used the first register, before transformation, and included 7,810 patients from 240 units. A majority of the registrations were made in two counties, both of which are populated areas. COPD is defined in the register by the Global initiative for chronic Obstructive Lung Disease definition, ie, with the spirometric criterion for airflow limitation that remains with a postbronchodilator ratio of forced expiratory volume in 1 second $\left(\mathrm{FEV}_{1}\right) /$ forced vital capacity of $<0.70 .{ }^{16}$ Registered items are demographic and clinical variables and appropriate interventions. The aim of the present study was to determine to what extent patients with COPD are offered evidencebased interventions and how the interventions are distributed across demographic and clinical factors in the sample.

\section{Methods}

The Swedish National Airway Register includes demographic and disease- and treatment-related variables. In the present study, the baseline registrations of 7,810 patients are presented. All patients who had been registered were included in the present study. Inclusion criterion was that the patient had at least one registration during the period in which the register was active. All registrations included in the present study concern baseline data. The study was approved by the Ethics Committee at the Department of Medical Ethics in Gothenburg in July 2015 (Dnr: 317-15). All patients were informed and gave their informed consent prior to entering the register.

\section{Hypotheses}

Hypotheses were formulated based on the pharmacological and nonpharmacological treatments recommended in COPD care and the assumption that the care should be distributed based on disease severity, irrespective of the sociodemographic factors.

Hypothesis I: Smoking cessation program is equally distributed to smokers across sociodemographic characteristics.

Hypothesis II: Patient education program is equally distributed across sociodemographic characteristics.

Hypothesis III: Dietician consultation is related to a low BMI, irrespective of the sociodemographic factors.

Hypothesis IV: Physiotherapy consultation is more common with deteriorating exercise capacity and increasing dyspnea, irrespective of the sociodemographic factors.

In order to find whether there are differences in the distribution of nonpharmacological and pharmacological treatments, two hypotheses about two pharmacological treatments were formulated.

Hypothesis V: Prescription of long-acting anticholinergics is more common with increasing disease severity measured by $\mathrm{FEV}_{1} \%$ of the predicted value, dyspnea, and exacerbations, irrespective of the sociodemographic factors.

Hypothesis VI: Prescription of the combination of longacting $\beta_{2}$-adrenoceptor agonists and inhaled steroids is more common with increasing disease severity measured by $\mathrm{FEV}_{1} \%$ of the predicted value, dyspnea, and exacerbations, irrespective of the sociodemographic factors. 


\section{Variables}

\section{Demographic and clinical variables}

We included demographic factors such as age, gender, and social situation, divided into "living alone" or "cohabiting", from the Swedish National Airway Register. Clinical variables included obstruction, measured by $\mathrm{FEV}_{1} \%$ of the predicted value, number of exacerbations during the last 12 months before registration, number of hospital admissions due to COPD in the last 12 months before registration, BMI, and comorbidities.

\section{Patient-reported variables}

Patient-reported variables were smoking (nonsmokers, quit smoking, or still smoking), exercise capacity, measured by number of days per week with physical activity, and functional dyspnea, measured by the modified Medical Research Council (mMRC) dyspnea scale. ${ }^{18}$ The mMRC dyspnea scale is a patient-reported, single-item scale where the severity of dyspnea is reported, ranging from 0 ("not troubled by breathlessness except on strenuous exercise") to 4 ("breathless when dressing or undressing"). HRQOL was measured by the Clinical COPD Questionnaire (CCQ),${ }^{19}$ a patient-rated questionnaire consisting of ten items: one item each about dyspnea at rest and dyspnea during physical activities; two items about how concerned the patient is about dyspnea; one item each about cough and phlegm; and four items about how the dyspnea had limited the patient's physical activities, ie, strenuous physical activities, moderate physical activities, daily activities, and social activities. All items are scored from 0 , for "never", to 6 , which corresponds to "almost all the time". Mean values of the scores were used and the results are interpreted as follows: 4.0-6.0 means large or very large impact on HRQOL/health status, 2.0-3.9 corresponds to moderate impact on HRQOL, and 0.0-1.9 means none or small impact on HRQOL.

\section{Treatment-related variables}

Data about interventions and treatments were retrieved from the Swedish National Airway Register. Participation in a smoking cessation program was included in the analysis for those who reported themselves as still smoking. Patient education program included: lectures to increase knowledge about COPD, medications, and prevention of infection; advice about physical activity, breathing, cough, and relaxation techniques, energy-conserving techniques; and daily life aids. Patient education also included appropriate actions to take during exacerbations, as well as smoking prevention and smoking cessation. Other information collected included if the patient had an established contact with physiotherapists, dieticians, occupational therapists, or social workers, and had received vaccinations against Streptococcus pneumoniae and influenza, as well as oxygen treatment. There was no information about the target of the consultations with physiotherapists, dieticians, occupational therapists, or social workers. Data on the following medications were also retrieved from the Swedish National Airway Register: long-acting anticholinergics, inhaled steroids, combination of steroids and long-acting $\beta_{2}$-adrenoceptor agonists, $\mathrm{N}$-acetylcysteine, calcium, bisphosphonate, and long-acting $\beta_{2}$-adrenoceptor agonists.

\section{Data analysis}

Descriptive statistics were used to describe the sample and registered treatments, with mean and standard deviation (SD) calculated for continuous variables. Categorical variables were presented as numbers and percentages for the total sample $(\mathrm{N}=7,810)$ and the distribution in the demographic groups, ie, for those below and above the median age of 70 years, for men and women, and for those living alone and those who cohabit. Some registrations were missed, resulting in lower numbers of participants in different variables, ie, missing registrations in any of the demographic or the investigated variables resulted in substantially lower numbers of some variables in Tables 1 and 2. Relationships between dichotomous categorical experience and treatment variables and age, gender, and social situation were analyzed with the Mantel-Haenszel chi-square test. Logistic binary regression analyses were used to analyze the relationships between treatments and selected prerequisites, as defined by the hypotheses, and adjusted for age, gender, and social situation. The treatments used as dependent variables were: participation in a smoking cessation or patient education program, dietician consultations, physiotherapy consultations, medication with long-acting anticholinergic and a combination of steroids and long-acting $\beta_{2}$-adrenoceptor agonists. First, univariable logistic regression analyses were performed with age, gender, social situation, $\mathrm{FEV}_{1} \%$ of the predicted value, BMI, exercise capacity, dyspnea measured by $\mathrm{mMRC}$, HRQOL measured by CCQ, and exacerbations per year as independent variables. Second, independent variables that significantly predicted the dependent variable with $P<0.20$ in the univariable analyses were entered in the multivariable logistic regression analyses with the same dependent variables. 


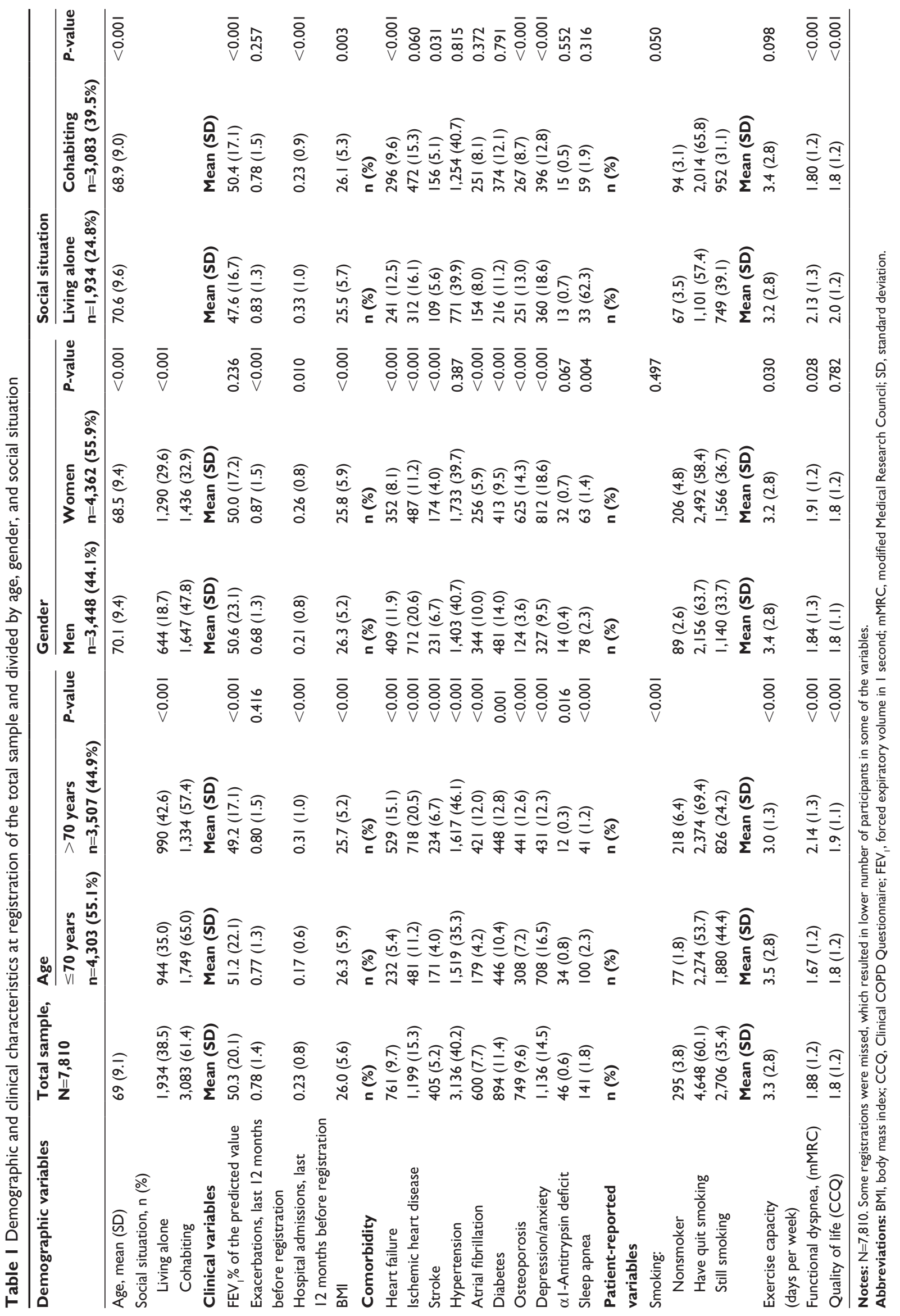




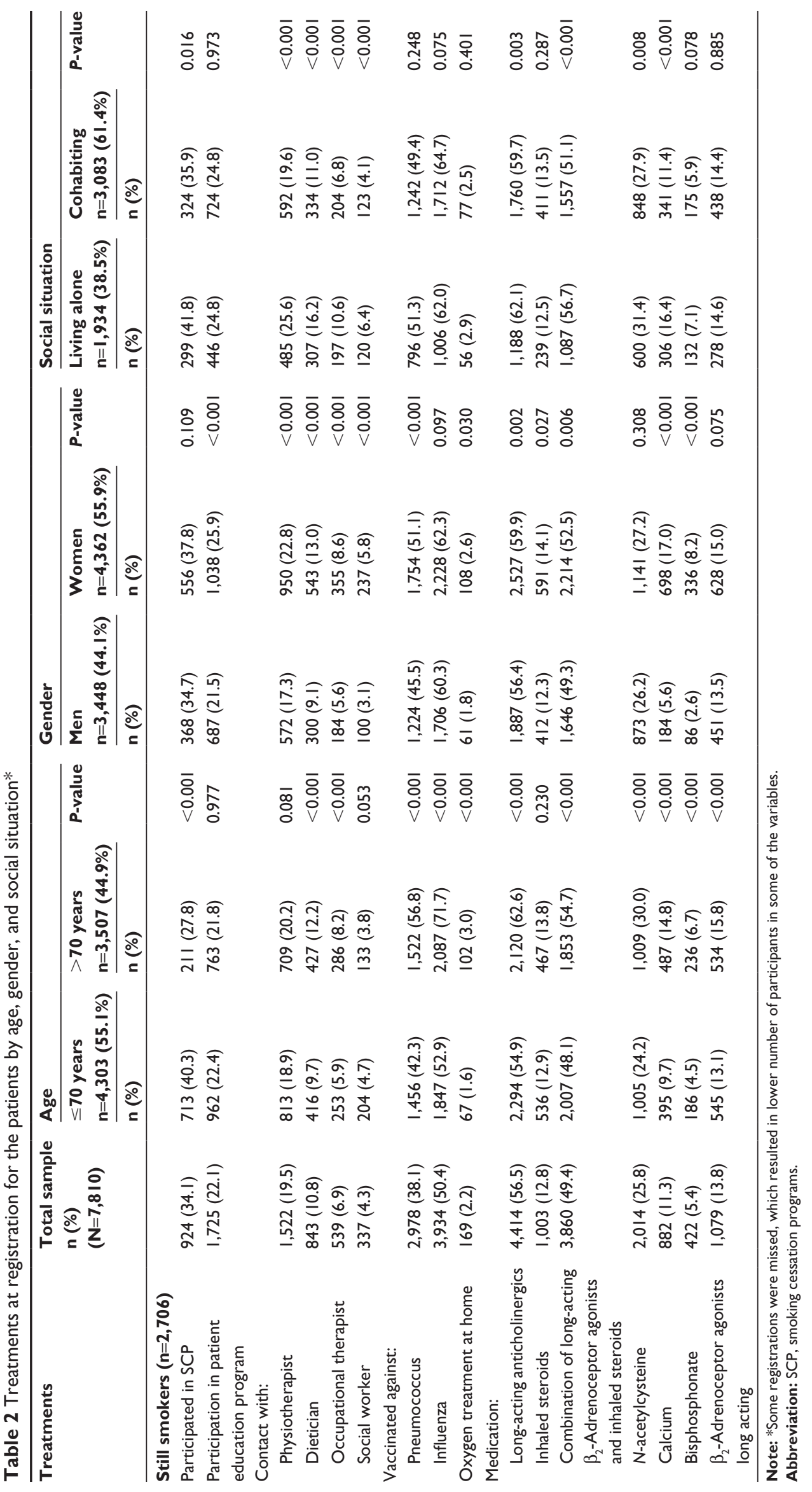


As the total sample was large and many comparisons were made, only those $P$-values $<0.001$ were regarded as significant.

\section{Results}

\section{Demographic and clinical characteristics}

Demographic and clinical characteristics of the patients are presented in Table 1. According to the Global initiative for chronic Obstructive Lung Disease staging, ${ }^{16}$ the majority of the patients $(48 \%)$ were diagnosed with moderate COPD $\left(50 \% \leq \mathrm{FEV}_{1},<80 \%\right.$ predicted). Seven percent of the patients were diagnosed with mild COPD $\left(\mathrm{FEV}_{1} \geq 80 \%\right.$ predicted), $35 \%$ with severe COPD $\left(30 \% \leq \mathrm{FEV}_{1},<50 \%\right.$ predicted $)$, and $10 \%$ with severe $\mathrm{COPD}\left(\mathrm{FEV}_{1}<30 \%\right.$ predicted). Men had more comorbidities than women, except for osteoporosis and depression/anxiety. Heart failure, osteoporosis, and depression were more frequently reported by those living alone. Younger people and men had higher BMI. People below 71 years of age were more commonly current smokers. Median exercise capacity was three days a week.

\section{Dyspnea and HRQOL}

The median subjectively rated dyspnea degree, according to the mMRC, was two, corresponding to "becoming breathless when walking on flat ground at the same speed as a person of the same age". Those living alone had higher levels of self-rated dyspnea than those who were cohabiting. Median HRQOL, according to CCQ, was 1.6, which corresponds to "little or no impact on HRQOL". Older people had worse HRQOL and worse dyspnea and less exercise capacity than younger people (Table 1).

\section{Treatments}

Hypotheses I and II: smoking cessation and education programs

The registered treatments are presented in Table 2. Of the current smokers, a minority (34\%) participated in a smoking cessation program. In the multivariable analyses, no factors were related to a changed odds ratio for participation in a smoking cessation program (Table 3). Of the total sample, $22 \%$ had participated in patient education programs, with women participating to a larger extent (Table 2). Worse dyspnea was the only significant variable that increased the odds of participation in patient education (Table 3 ).

\section{Hypotheses III and IV: physiotherapist and} dietician contacts

Physiotherapy was the most common paramedic consultation. Being a woman and living alone were the factors associated with an increased possibility of having contact with a physiotherapist. Increasing age, being a woman, and living alone were the factors associated with an increased possibility of having contact with a dietician.

In a multivariable analysis adjusted for age, gender, and social situation, an increasing possibility for having contact with a dietician or a physiotherapist was related to lower $\mathrm{FEV}_{1} \%$ of the predicted value, higher levels of dyspnea, worse HRQOL, and higher number of exacerbations. Lower BMI was also a positive factor for having contact with a dietician (Table 3).

\section{Hypotheses V and VI: pharmacological treatments}

Patients of increasing age were, to a larger extent, prescribed long-acting anticholinergics and a combination of steroids and long-acting $\beta_{2}$-adrenoceptor agonists. The likelihood of being prescribed long-acting anticholinergics increased with low $\mathrm{FEV}_{1} \%$ of the predicted value and higher levels of dyspnea (Table 4). The likelihood of being prescribed a combination of inhaled corticosteroids and long-acting $\beta_{2}$-adrenoceptor agonists increased with low $\mathrm{FEV}_{1} \%$, increased level of dyspnea, worse HRQOL, and an increased exacerbation rate (Table 4).

\section{Discussion}

The present study shows that patients with COPD are not a homogenous group and that there are differences in disease expressions as well as in treatments related to demographic characteristics. These differences could have various explanations, such as different characteristics of the disease or differences in prescriptions of treatment across age, gender, and social situation. Nonpharmacological treatments were only used by a minority of the patients, and could, if prescribed and utilized to larger extent, have the potential to increase the effectiveness of COPD treatment.

With regard to disease characteristics, more men than women were diagnosed with comorbidities, except for osteoporosis and depression/anxiety, which occurred more frequently in women, which was also reported by Aryal et al. ${ }^{4}$ Differences in comorbidity profile were also found by Kilic et al, ${ }^{20}$ who reported that women, to a larger extent, had sleep disorder, chronic kidney disease, anemia, and gastroesophageal reflux disease ${ }^{20}$ The present study, as in the study by Kilic et al,${ }^{20}$ showed that women experienced significantly more exacerbations. However, the increase of exacerbations in relation to higher age, found in other studies, ${ }^{79}$ was not found in this sample. The most probable explanation for the difference is that the selection criteria of the patients were different in these studies. Our patient register is dominated 


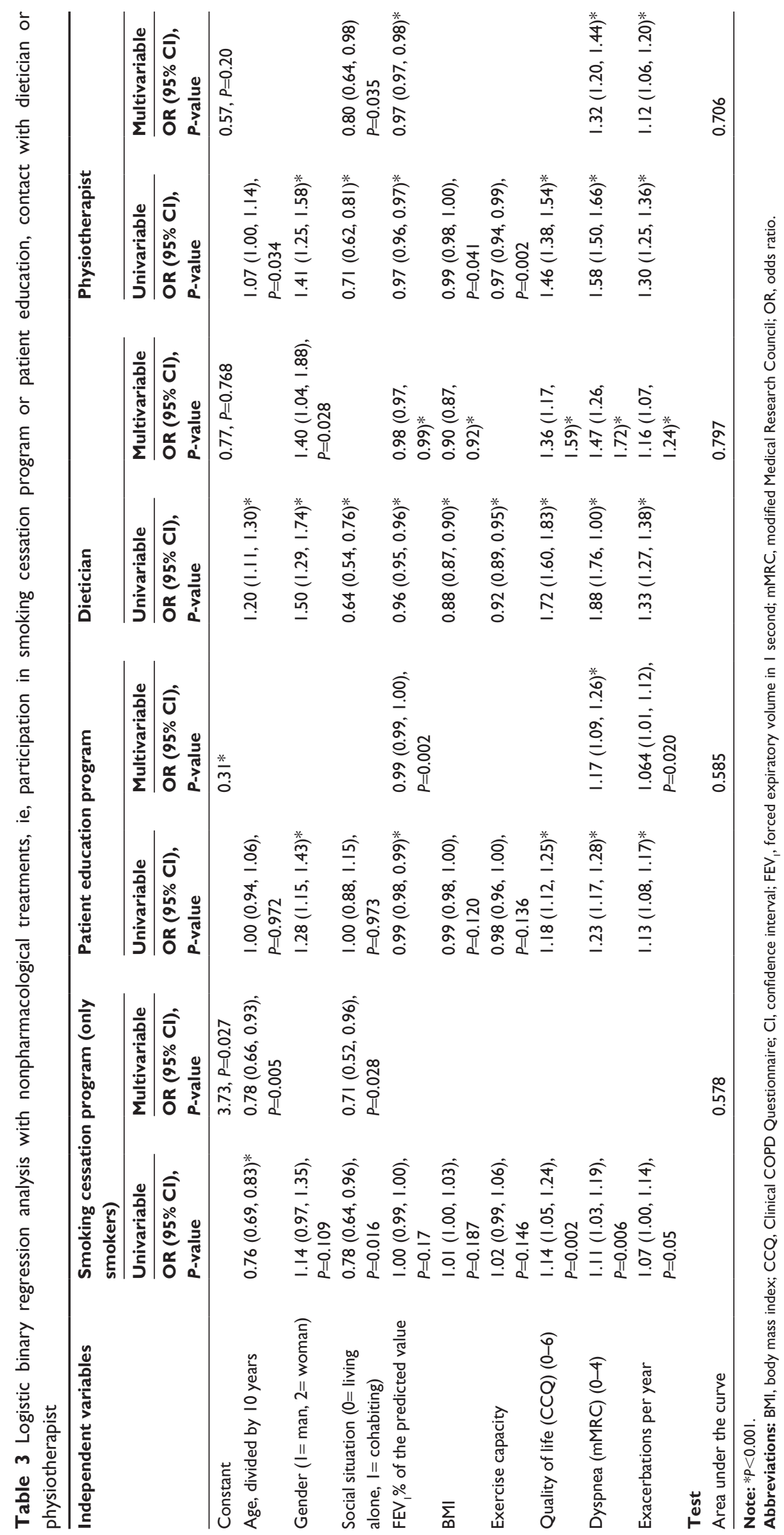


Table 4 Logistic binary regression analysis with pharmacological treatments, ie, prescriptions of long-acting anticholinergics and a combination of steroids and long-acting $\beta_{2}$-adrenoceptor agonists as dependent variables

\begin{tabular}{|c|c|c|c|c|}
\hline \multirow[t]{3}{*}{ Independent variables } & \multicolumn{2}{|c|}{$\begin{array}{l}\text { Prescription of long-acting } \\
\text { anticholinergics }\end{array}$} & \multicolumn{2}{|c|}{$\begin{array}{l}\text { Prescription of a combination of } \\
\text { long-acting } \beta_{2} \text {-adrenoceptor agonists } \\
\text { and inhaled steroids }\end{array}$} \\
\hline & Univariable & Multivariable & Univariable & Multivariable \\
\hline & $\begin{array}{l}\text { OR }(95 \% \mathrm{Cl}) \text {, } \\
P \text {-value }\end{array}$ & OR (95\% Cl) & $\begin{array}{l}\text { OR }(95 \% \mathrm{Cl}) \\
P \text {-value }\end{array}$ & OR (95\% Cl) \\
\hline Constant & & $1.61, P=0.008$ & & $\mathrm{I} .58, P=0.007$ \\
\hline Age, divided in 10 years & $1.25(1.19,1.32)^{*}$ & & $1.19(1.13,1.24)^{*}$ & \\
\hline Gender ( $I=$ man, $2=$ woman $)$ & $\begin{array}{l}1.16(1.05,1.27) \\
P=0.002\end{array}$ & & $\begin{array}{l}I .14(1.04,1.24) \\
P=0.006\end{array}$ & \\
\hline $\begin{array}{l}\text { Social situation }(0=\text { living } \\
\text { alone, } \mathrm{I}=\text { cohabiting) }\end{array}$ & $\begin{array}{l}0.84(0.74,0.94) \\
P=0.003\end{array}$ & & $0.80(0.7 \mathrm{I}, 0.90)^{*}$ & \\
\hline $\mathrm{FEV}_{1} \%$ of the predicted value & $0.98(0.97,0.98)^{*}$ & $0.99(0.98,0.99)^{*}$ & $0.97(0.97,0.97)^{*}$ & $0.98(0.97,0.98) *$ \\
\hline BMI & $\begin{array}{l}0.99(0.98,1.00) \\
P=0.121\end{array}$ & & $\begin{array}{l}1.00(0.99,1.01) \\
P=0.709\end{array}$ & \\
\hline Exercise capacity & $\begin{array}{l}1.00(0.98,1.02) \\
P=0.766\end{array}$ & & $\begin{array}{l}0.99(0.97,1.00) \\
P=0.985\end{array}$ & \\
\hline Quality of life (CCQ) & $1.35(1.28,1.42)^{*}$ & & $1.56(1.48,1.64)^{*}$ & $1.19(1.09,1.30) *$ \\
\hline Dyspnea (mMRC) & $1.46(1.40,1.52)^{*}$ & $1.30(1.20,1.40)^{*}$ & $1.56(1.50,1.63)^{*}$ & $1.22(1.13,1.33)^{*}$ \\
\hline Exacerbations per year & $1.18(1.13,1.23)^{*}$ & $\begin{array}{l}1.08(1.01,1.15) \\
P=0.026\end{array}$ & $1.38(1.32,1.45)^{*}$ & $1.16(1.08,1.24)^{*}$ \\
\hline Test & & & & \\
\hline Area under the curve & & 0.658 & & 0.694 \\
\hline
\end{tabular}

Note: $* P<0.001$

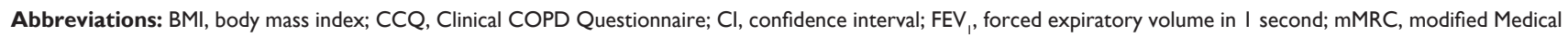
Research Council; OR, odds ratio.

by patients from primary care, and a substantial part of our patients were in the early stages of the disease.

Regarding variation in the prescription of interventions, there were some differences between men and women in the reported treatments (Table 2), in that more women participated in patient education programs, had contacts with physiotherapists, occupational therapists, dietician, and social workers, were vaccinated, and received more pharmacological interventions. Although women have earlier been found to have a longer diagnostic delay and increased difficulties of reaching a physician, ${ }^{21}$ there are no consistent findings of gender differences in treatments in the earlier studies, ${ }^{22}$ as we found in the present study. An explanation of the gender differences could be an inherent difference in the appreciation of, for example, rehabilitation efforts. The sociodemographic differences did not remain in the multivariable analysis and the first and the second hypotheses were supported, in that there were no sociodemographic differences in participation in smoking cessation or patient education programs. The national guidelines for evidencebased COPD management, published in Sweden in $2015^{23}$ by the National Board of Health and Welfare, state that patient education and smoking cessation support should be offered with high priority to all patients with COPD. Therefore, it is reassuring that these nonpharmacological interventions are equally distributed across sociodemographic factors.

The guidelines ${ }^{23}$ further recommend different types of interventions concurrently, such as support from an interprofessional team with physiotherapy and dietician contact. Only $11 \%$ of the registered patients had dietician contact, and it was found that patients with lower BMI and deteriorating disease were more likely to have dietician contact. This, to some extent, supports the third hypothesis that dietician consultation is related to BMI, independent of sociodemographics. According to the European Society for Clinical Nutrition and Metabolism guidelines, nutrition is important for COPD patients and should, in combination with exercise and pharmacological therapy, increase the nutritional status. ${ }^{24}$

Only $20 \%$ of the patients had contact with a physiotherapist, which is too low, according to the recommendation in the current guidelines which states that patients with deteriorated physical capacity should be offered fitness training. The mean days of exercise in the sample was slightly above three days a week, across age, gender, and social situation. Contact with a physiotherapist was predicted by increased dyspnea and higher exacerbation frequency, but not by deteriorated exercise capacity, which means that the fourth hypothesis, which assumed that physiotherapy contact should 
be more common with deteriorating exercise capacity, was not supported. This indicates that deteriorated illness, with increasing dyspnea, is the main trigger of physiotherapy consultation. The physiotherapy consultation is part of pulmonary rehabilitation, with the potential to improve both dyspnea and exercise capacity. ${ }^{13}$ In the guidelines, ${ }^{23}$ it was stated that health care professionals should identify patients with deteriorated physical capacity with a 6-minute walking test and offer fitness training, individually or in a group, which could be a good way to improve the implementation of training and rehabilitation in the management of COPD.

The Swedish Medical Products Agency has published the recommendations for medical treatment offered to patients with COPD and dyspnea, measured by the $\mathrm{mMRC}^{18} \geq 2.0$ and $\mathrm{CCQ}^{19} \geq 1.0$, which includes long-acting anticholinergics or a combination of long-acting anticholinergics and long-acting $\beta_{2}$-adrenoceptor agonists. If the patients also have exacerbations, long-acting $\beta_{2}$-adrenoceptor agonists combined with inhaled steroids is a starting option. ${ }^{25}$ Prescription of longacting anticholinergics was more common in patients with lower $\mathrm{FEV}_{1} \%$ and increased dyspnea, which was the fifth hypothesis and is in accordance with the recommendations. Prescription of a combination of long-acting $\beta_{2}$-adrenoceptor agonists and inhaled corticosteroids was more common in patients with low $\mathrm{FEV}_{1} \%$, deteriorated HRQOL, increased dyspnea, and increased exacerbation frequency, supporting hypothesis VI, which states that a combination of long-acting $\beta_{2}$-adrenoceptor agonists and inhaled steroids is prescribed commonly with increasing disease severity as measured by $\mathrm{FEV}_{1} \%$ of the predicted value, dyspnea, and exacerbations, irrespective of the sociodemographic factors.

There were differences in clinically measured and patientreported variables and in comorbidity between older and younger patients, men and women, and those living alone and those cohabiting; however, the triggering factors for prescriptions of pharmacological treatment seem to be deteriorated illness, uninfluenced by demographic factors. The results also imply that the pharmacological treatments were, to a larger extent, following the newly formulated guidelines, in contrast to the recommended nonpharmacological interventions. However, the present study shows that both pharmacological and nonpharmacological treatments were prescribed according to the severity of the disease, irrespective of age, gender, and social situation.

\section{Methodological considerations}

A comprehensively completed register provides the opportunity to compare management and outcomes in a real-life situation. ${ }^{17}$ To obtain evidence for an intervention, evidence-based medicine mostly employs randomized controlled trials or meta-analyses, which provide highly stringent results of the efficacy of an intervention. However, the stringency in the trial situation might not always be possible in an encounter with the real-life situation of a patient. Using a quality register has the potential to generate knowledge about the effects of interventions on large populations. ${ }^{26}$ Sometimes, epidemiological studies can provide this type of information. The reverse, however, is that epidemiology tends to underestimate the effects of disease management in the more severely ill patients. Thus, although not comprehensive in either geographical coverage or inclusion of all patients in each health care center, the register could give information on what is possible in the real patient encounter and provides the possibility to adhere to guidelines.

Limitations of our study include its retrospective approach. In order to improve generalization of the register, it is important to obtain comprehensive registration across all regions and all health care centers dealing with COPD in the country. Also, a better representation of the early stages of COPD following a better diagnostic effort will further improve the generalization of a register such as ours.

\section{Conclusion}

The present study showed that although there were differences between both disease expressions and management across demographic characteristics, treatments are mainly related to disease severity. Only a minority of the patients in the present study participated in interventions from the interdisciplinary team. Therefore, there is a great potential for improvement to keep up with the current national guidelines and use pharmacological and nonpharmacological interventions concurrently. Quality registers have the strength to follow-up on compliance with guidelines and, to some extent, also evaluate the important factors in guideline implementation.

\section{Disclosure}

The authors report no conflicts of interest in this work.

\section{References}

1. Soler-Cataluna JJ, Martinez-Garcia MA, Sanchez LS, Tordera MP, Sanchez PR. Severe exacerbations and BODE index: two independent risk factors for death in male COPD patients. Respir Med. 2009;103(5): 692-699.

2. Gershon AS, Dolmage TE, Stephenson A, Jackson B. Chronic obstructive pulmonary disease and socioeconomic status: a systematic review. COPD. 2012;9(3):216-226

3. Laaksonen M, Rahkonen O, Karvonen S, Lahelma E. Socioeconomic status and smoking: analysing inequalities with multiple indicators. Eur J Public Health. 2005;15(3):262-269. 
4. Aryal S, Diaz-Guzman E, Mannino DM. COPD and gender differences: an update. Transl Res. 2013;162(4):208-218.

5. Watson L, Vestbo J, Postma DS, et al. Gender differences in the management and experience of chronic obstructive pulmonary disease. Respir Med. 2004;98(12):1207-1213.

6. Ståhl E, Lindberg A, Jansson SA, et al. Health-related quality of life is related to COPD disease severity. Health Qual Life Outcomes. 2005;3:56.

7. Miravitlles M, Guerrero T, Mayordomo C, Sanchez-Agudo L, Nicolau F, Segu JL. Factors associated with increased risk of exacerbation and hospital admission in a cohort of ambulatory COPD patients: a multiple logistic regression analysis. The EOLO study group. Respiration. 2000;67(5):495-501.

8. Niewoehner DE, Lokhnygina Y, Rice K, et al. Risk indexes for exacerbations and hospitalizations due to COPD. Chest. 2007;131(1):20-28.

9. Jarad N. Chronic obstructive pulmonary disease (COPD) and old age? Chron Respir Dis. 2011;8(2):143-151.

10. Connors AF Jr, Dawson NV, Thomas C, et al. Outcomes following acute exacerbation of severe chronic obstructive lung disease. The SUPPORT investigators (Study to understand prognoses and preferences for outcomes and risks of treatments). Am J Respir Crit Care Med. 1996;154(4 Pt 1):959-967.

11. Gallefoss F. The effects of patient education in COPD in a 1-year follow-up randomised, controlled trial. Patient Educ Couns. 2004;52(3): 259-266.

12. Bourbeau J, Julien M, Maltais F, et al. Reduction of hospital utilization in patients with chronic obstructive pulmonary disease: a diseasespecific self-management intervention. Arch Intern Med. 2003;163(5): $585-591$.

13. Celli BR, Cote CG, Lareau SC, Meek PM. Predictors of survival in COPD: more than just the $\mathrm{FEV}_{1}$. Respir Med. 2008;102(Suppl 1): S27-S35.

14. Cote CG, Celli BR. Pulmonary rehabilitation and the BODE index in COPD. Eur Respir J. 2005;26(4):630-636.

15. Garrod R, Lasserson T. Role of physiotherapy in the management of chronic lung diseases: an overview of systematic reviews. Respir Med. 2007;101(12):2429-2436.

16. Vestbo J, Hurd SS, Agusti AG, et al. Global strategy for the diagnosis, management, and prevention of chronic obstructive pulmonary disease: GOLD executive summary. Am J Respir Crit Care Med. 2013;187(4):347-365.

17. Ovretveit J, Keller C, Hvitfeldt Forsberg H, Essen A, Lindblad S, Brommels M. Continuous innovation: developing and using a clinical database with new technology for patient-centred care - the case of the Swedish quality register for arthritis. Int J Qual Health Care. 2013;25(2): 118-124.
18. Bestall JC, Paul EA, Garrod R, Garnham R, Jones PW, Wedzicha JA. Usefulness of the Medical Research Council (MRC) dyspnoea scale as a measure of disability in patients with chronic obstructive pulmonary disease. Thorax. 1999;54(7):581-586.

19. van der Molen T, Willemse BW, Schokker S, ten Hacken NH, Postma DS, Juniper EF. Development, validity and responsiveness of the clinical COPD questionnaire. Health Qual Life Outcomes. 2003;1:13.

20. Kilic H, Kokturk N, Sari G, Cakir M. Do females behave differently in COPD exacerbation? Int J Chron Obstruct Pulmon Dis. 2015;10: 823-830.

21. Martinez CH, Raparla S, Plauschinat CA, et al. Gender differences in symptoms and care delivery for chronic obstructive pulmonary disease. $J$ Womens Health (Larchmt). 2012;21(12):1267-1274.

22. Camp PG, Goring SM. Gender and the diagnosis, management, and surveillance of chronic obstructive pulmonary disease. Proc Am Thorac Soc. 2007;4(8):686-691.

23. Swedish National Board of Health and Welfare [Socialstyrelsen]. National guidelines for care of asthma and COPD. Support for management and administration. [Swedish: Nationella riktlinjer för vård vid astma och KOL. Stöd för styrning och ledning]. 2015 [cited 2015 Nov 26]. Available from: http://www.socialstyrelsen.se/ Lists/Artikelkatalog/Attachments/19949/2015-11-3.pdf. Accessed November 11, 2015.

24. Anker SD, John M, Pedersen PU, et al. ESPEN guidelines on enteral nutrition: ardiology and pulmonology. Clin Nutr. 2006;25(2):311-318.

25. Swedish Medical Products Agency [Läkemedelsverket]. Chronic Obstructive Pulmonary Disease (COPD) - treatment recommendations [Swedish: Kronisk obstruktiv lungsjukdom (KOL) - behandlingsrekommendationer. 2015[cited 2015 Nov 26]. Available from: https:// lakemedelsverket.se/kol. Accessed November 11, 2015. Swedish.

26. Bohlin I. Evidence-based desicion-making in a scientific society. About the evidence movement's origin, dispersion and limits. [Swedish: Evidensbaserat beslutsfattande i ett vetenskapligt samhälle. Om evidensrörelsens ursprung, utbredning och gränser.] In: Bohlin I, Sager M, editors. The Many Faces of the Evidence. Evidence-Based Practice in Practice. [Swedish: Evidensens många ansikten. Evidensbaserad praktik i praktiken]. Lund: Arkiv förlag; 2011:31-68. Swedish.
International Journal of COPD

\section{Publish your work in this journal}

The International Journal of COPD is an international, peer-reviewed journal of therapeutics and pharmacology focusing on concise rapid reporting of clinical studies and reviews in COPD. Special focus is given to the pathophysiological processes underlying the disease, intervention programs, patient focused education, and self management protocols.

\section{Dovepress}

This journal is indexed on PubMed Central, MedLine and CAS. The manuscript management system is completely online and includes a very quick and fair peer-review system, which is all easy to use. Visit http://www.dovepress.com/testimonials.php to read real quotes from published authors. 